\title{
Desynapsis due to Temperature Stress in Three Species of Solanum L.
}

\author{
J. L. Karihaloo \\ National Facility for Plant Tissue Culture Repository, \\ National Bureau of Plant Genetic Resources, Pusa Campus, \\ New Delhi 110012, India
}

Accepted June 27, 1991

S. melongena L., brinjal or eggplant, is a popular vegetable crop of India grown throughout the country in varied agroclimatic conditions. Flowering and fruit set are influenced by season fruit size and per plant yield being higher in the summer crop than in the winter crop (Som and Maity 1986). Low temperature is reported to cause abnormal development of flower buds in some varieties of $S$. melongena resulting in "splitting" of the ovary (Nothmann and Koller 1973). However, the effects of adverse environment on its microsporogenesis are not known. During the course of studies on interrelationships in the genus Solanum, pollen viability in $S$. melongena and 2 wild species, $S$. torvum Swartz and $S$. violaceum Jacq. was observed to show marked changes from one season to the other. Study of male meiosis revealed the occurrence of normal meiosis during the main flowering season and desynapsis during off-season flowering. Desynapsis or dissociation of chromsomes shortly after pairing is known to be caused by a variety of factors including spontaneous and induced gene mutations and different environmental stresses (Koduru and Rao 1981, Kaul and Murthy 1985). The present communication gives details of desynapsis caused by the stress of hight temperature in $S$. torvum and low temperature in $S$. melongena and $S$. violaceum.

\section{Materials and methods}

S. torvum Acc. no. JL-87, S. melongena cv. IHR 133, and $S$. violaceum Acc. no. JL-57 were grown in net house at Delhi in northern India. Four to 6 plants each were maintained in growing condition throughout the year by regular watering and fertilization. Flowering in these took place almost throughout the year with brief breaks of 1-3 months. Male meiosis was studied more than once from buds produced during different flowering seasons.

Flower buds at appropriate stages of division were fixed in 1:3 acetic-alcohol for $10 \mathrm{~min}$. Squashes were prepared in $1 \%$ aceto-orcein and studies made from temporary slides. Chiasma frequency was determined from 30 metaphase cells. Pollen stainability was studied with $1 \%$ acetocarmine.

\section{Observations}

\section{S. torvum}

Normal meiosis was observed during October-November flowering (average max. temp. $30.2^{\circ} \mathrm{C}$, average min. temp. $14.2^{\circ} \mathrm{C}$ ). The 24 chromosomes paired into 12 bivalents (Fig. 1) which segregated normally at anaphase. Chiasma frequency per cell was 19.50 while per bivalent it was 1.62 (Table 1). Pollen stainability during this period was as high as $93.4 \%$.

Desynaptic behaviour was observed in July during summer flowering (average max. temp. $34.1^{\circ} \mathrm{C}$, average min. temp. $26.1^{\circ} \mathrm{C}$ ). Both diplotene and metaphase stages were suitable for 
observation. At diplotene, $57.58 \%$ cells showed normal pairing of chromosomes into 12 bivalents (Table 2). The rest had 2 to 8 univalents in addition to the complementary number of bivalents. The average per cell association at this stage was $11.21 \mathrm{II}+1.58 \mathrm{I}$. At metaphase I, there was a drastic reduction in the number of bivalents. Thus $68.41 \%$ cells at this stage had 6 or fewer bivalents (Figs. 2, 3, Table 3). The average chromosome association was $5.72 \mathrm{II}+12.56 \mathrm{I}$ per cell. Chiasma frequency was 5.32 per cell and 1.05 per bivalent (Table 1). By the beginning of anaphase, the univalents had moved towards the poles or were distributed near the periphery of the cells whereas the bivalents remained in the centre. As such, the transition from metaphase to anaphase was not well demarcated. Later when the bivalents had resolved into univalents, the chromsomes were mostly unequally distributed at the 2 poles and had upto 7 laggards in the centre (Table 4). The sporogenous tissue collapsed soon afterwards and the anthers shrivelled before the microspores could mature into pollen grains.

Table 1. Metaphase chiasma frequency in Solanum species. Figures represent mean values and standard deviations (in parentheses)

\begin{tabular}{|c|c|c|c|c|}
\hline \multirow{2}{*}{$\begin{array}{c}\text { Nature of } \\
\text { meiosis }\end{array}$} & \multicolumn{4}{|c|}{ Chiasma frequency } \\
\hline & & Interstitial & Terminal & Total \\
\hline & \multicolumn{4}{|c|}{ S. torvum } \\
\hline \multirow[t]{2}{*}{ normal } & per cell & $6.60(1.724)$ & $12.90(2.146)$ & $19.50(1.962)$ \\
\hline & per bivalent & $0.55(0.144)$ & $1.08(0.183)$ & $1.62(0.164)$ \\
\hline \multirow[t]{3}{*}{ desynaptic } & per cell & $3.10(1.850)$ & $2.13(1.431)$ & $5.23(2.231)$ \\
\hline & per bivalent & $0.40(0.278)$ & $0.65(0.302)$ & $1.05(0.086)$ \\
\hline & \multicolumn{4}{|c|}{ S. melongena } \\
\hline \multirow[t]{2}{*}{ normal } & per cell & $5.20(1.851)$ & $12.10(2.181)$ & $17.30(1.865)$ \\
\hline & per bivalent & $0.43(0.154)$ & $1.01(0.182)$ & $1.44(0.155)$ \\
\hline \multirow[t]{3}{*}{ desynaptic } & per cell & $3.47(2.045)$ & $6.30(2.410)$ & $9.76(3.084)$ \\
\hline & per bivalent & $0.45(0.213)$ & $0.81(0.193)$ & $1.26(0.135)$ \\
\hline & \multicolumn{4}{|c|}{ S. violaceum } \\
\hline \multirow[t]{2}{*}{ normal } & per cell & $6.93(2.264)$ & $13.30(3.057)$ & $20.23(2.231)$ \\
\hline & per bivalent & $0.58(0.185)$ & $1.11(0.250)$ & $1.69(0.186)$ \\
\hline \multirow[t]{2}{*}{ desynaptic } & per cell & $2.67(1.854)$ & $9.57(3.954)$ & $12.23(4.693)$ \\
\hline & per bivalent & $0.27(0.176)$ & $1.01(0.238)$ & $1.28(0.217)$ \\
\hline
\end{tabular}

\section{S. melongena}

Male meiosis and seed set were normal during April and September (average max. temp. $35.8^{\circ} \mathrm{C}$ and $32.8^{\circ} \mathrm{C}$ respectively, average min. temp. $19.4^{\circ} \mathrm{C}$ and $24.4^{\circ} \mathrm{C}$ respectively), the two warm season months during which observations were made in this species. The 24 chromosomes invariably formed bivalents which remained paired till the onset of anaphase (Fig. 4). At metaphase, the chiasma frequency per cell and per bivalent was 17.30 and 1.44 respectively (Table 1). Segregation of chromosomes was normal 12:12 and pollen stainability as high as $94.6 \%$.

Examination of male meiosis in February during winter flowering (average max. temp. $21.0^{\circ} \mathrm{C}$, average min. temp. $7.5^{\circ} \mathrm{C}$ ) revealed desynapsis. Diplotene chromosomes were too poorly stained to provide reliable data on early pairing behaviour. At metaphase, one or more bivalents were invariably dissociated into univalents (Fig. 5, Table 3). The average per cell association was $7.63 \mathrm{II}+8.73 \mathrm{I}$. Chiasma frequency at metaphase I was 9.76 per cell and 1.26 per bivalent (Table 1). Two out of 26 cells at anaphase showed regular 12: 12 segregation. The rest showed unequal segregation, univalent laggards ranging upto 4 , and precociously dividing univalents (Fig. 6, Table 5). Pollen stainability was 14.7\%. Similar desynaptic behaviour was observed during the winter of next year also. 


\section{S. violaceum}

This species behaved like $S$. melongena in that the meiosis was normal during warm months of May and October (average max. temp. $38.2^{\circ} \mathrm{C}$ and $32.2^{\circ} \mathrm{C}$ respectively, average min. temp. $24.5^{\circ} \mathrm{C}$ and $16.7^{\circ} \mathrm{C}$ respectively) and desynaptic during January-February in winter (average

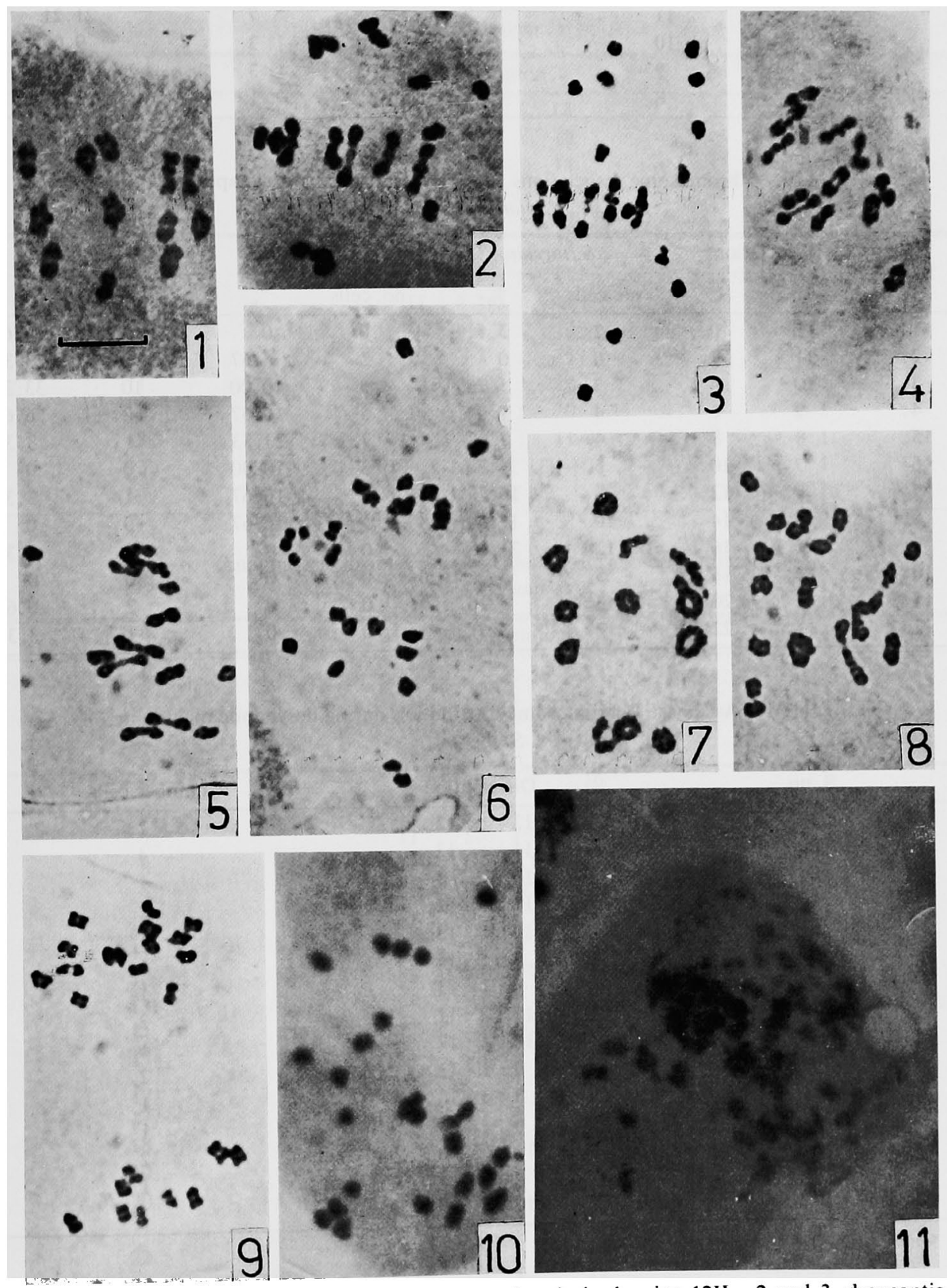

Figs. 1-11. 1-3: Meiosis in S. torvum. 1, normal meiosis showing 12II. 2 and 3, desynaptic meiosis. 2, 6II +12I. 3, 5II+14I. 4-6: Meiosis in S. melongena. 4, normal meiosis showing 12II. 5 and 6, desynaptic meiosis. 5, 10II $+4 \mathrm{I}$. 6, 10:4:10; note 4 chromsomes in the centre of the cell showing precicious chromatid separation. Figs. 7-11: Meiosis in $S$. violaceum. 7, normal meiosis showing 12II. 8-11, desynaptic meiosis. $\quad 8,8 \mathrm{II}+8 \mathrm{I}$. 9,15:9. 10,24I. 11, chromosome fragmentation. Scale $=5 \mu \mathrm{m}$ is uniform for all the figures. 
Table 2. Chromosome associations at diplotene during desynaptic meiosis in S. torvum

\begin{tabular}{crrrrr}
\hline \hline & \multicolumn{3}{c}{ Associations } & & \multicolumn{2}{c}{ Cells } \\
\cline { 2 - 3 } \cline { 5 - 6 } S. no. & II & I & & number & per cent \\
\hline 1. & 12 & 0 & & 19 & 57.58 \\
2. & 11 & 2 & & 7 & 21.21 \\
3. & 10 & 4 & & 3 & 9.09 \\
4. & 9 & 6 & & 3 & 9.09 \\
5. & 8 & 8 & & 1 & 3.03 \\
\hline
\end{tabular}

Table 3. Chromosome associations at metaphase I during desynaptic meiosis in Solanum species

\begin{tabular}{|c|c|c|c|c|c|c|c|c|}
\hline \multirow{2}{*}{ S. no } & \multicolumn{2}{|c|}{ Associations } & \multicolumn{2}{|c|}{ S. torvum } & \multicolumn{2}{|c|}{ S. melongena } & \multicolumn{2}{|c|}{ S. violaceum } \\
\hline & II & $\mathrm{I}$ & no. cells & $\%$ & no. cells & $\%$ & no. cells & $\%$ \\
\hline 1. & 12 & 0 & 2 & 3.51 & 0 & 0 & 5 & 16.67 \\
\hline 2. & 11 & 2 & 0 & 0 & 2 & 6.67 & 7 & 23.33 \\
\hline 3. & 10 & 4 & 3 & 5.26 & 3 & 10.00 & 10 & 33.33 \\
\hline 4. & 9 & 6 & 4 & 7.02 & 5 & 16.67 & 2 & 6.67 \\
\hline 5. & 8 & 8 & 4 & 7.02 & 7 & 23.33 & 1 & 3.33 \\
\hline 6. & 7 & 10 & 5 & 8.77 & 3 & 10.00 & 0 & 0 \\
\hline 7. & 6 & 12 & 9 & 15.79 & 5 & 16.67 & 1 & 3.33 \\
\hline 8. & 5 & 14 & 10 & 17.54 & 5 & 16.67 & 0 & 0 \\
\hline 9. & 4 & 16 & 12 & 21.05 & 0 & 0 & 1 & 3.33 \\
\hline 10. & 3 & 18 & 3 & 5.26 & 0 & 0 & 0 & $\mathbf{0}$ \\
\hline 11. & 2 & 20 & 3 & 5.26 & 0 & 0 & 2 & 6.67 \\
\hline 12. & 1 & 22 & 2 & 3.51 & 0 & 0 & 1 & 3.33 \\
\hline
\end{tabular}

Table 4. Anaphase I chromosome distribution during desynaptic meiosis in

S. torvum

\begin{tabular}{ccc}
\hline \hline S. no. & Distribution & number cells \\
\hline 1. & $12: 12$ & 2 \\
2. & $11: 13$ & 4 \\
3. & $10: 14$ & 1 \\
4. & $11: 1: 12$ & 2 \\
5. & $10: 1: 13$ & 1 \\
6. & $9: 1: 14$ & 1 \\
7. & $8: 1: 15$ & 1 \\
8. & $11: 2: 11$ & 2 \\
9. & $10: 2: 12$ & 1 \\
10. & $9: 3: 12$ & 2 \\
11. & $8: 3: 13$ & 1 \\
12. & $6: 3: 15$ & 1 \\
13. & $11: 5: 8$ & 2 \\
14. & $9: 6: 9$ & 1 \\
15. & $10: 7: 7$ & 1 \\
\hline
\end{tabular}

max. temp. $21.9^{\circ} \mathrm{C}$, average min. temp. $10.1^{\circ} \mathrm{C}$ ). Normal pairing resulted in 12 bivalents (Fig. 7) and regular segregation followed by high pollen fertility $(86.5 \%)$ and seed set. Chiasma frequency at metaphase I was 20.23 per cell and 1.69 per bivalent (Table 1).

Desynaptic meiosis was studied from buds fixed a number of times during the winter season of 2 succeeding years. Since most of the collections showed similar average frequencies 
of various configurations, data from only one of these are presented below. Meiosis was characterized by the presence of univalents and bivalents at metaphase (Fig. 8) and irregular anaphase segregation (Fig. 9). Twenty five out of the 30 cells studied at metaphase I showed 2

Table 5. Anaphase I chromosome distribution during desynaptic meiosis in S. melongena

\begin{tabular}{cccccc}
\hline \hline S. no. & \multicolumn{3}{c}{ Distribution } & number cells \\
\hline 1. & 12 & $:$ & 12 & 2 \\
2. & 11 & $:$ & 13 & 3 \\
3. & 10 & $:$ & 14 & 1 \\
4. & $11:$ & 1 & $:$ & 12 & 7 \\
5. & $11: 2$ & $1 / 2:$ & 12 & 1 \\
6. & $10:$ & 1 & $:$ & 13 & 2 \\
7. & $11:$ & 2 & $:$ & 11 & 1 \\
8. & $11: 4$ & $1 / 2:$ & 11 & 1 \\
9. & $10: 4$ & $1 / 2:$ & 12 & 1 \\
10. & $10: 5$ & 3 & $:$ & 11 & 1 \\
11. & $9: 6$ & $1 / 2:$ & 12 & 1 \\
12. & $10:$ & 4 & $:$ & 10 & 1 \\
13. & $9:$ & 4 & $:$ & 11 & 1 \\
13. & $10+4$ & $1 / 2: 2$ & $1 / 2+11$ & 1 \\
15. & $8+8$ & $1 / 2: 8$ & $1 / 2+8$ & 8 \\
\hline
\end{tabular}

Table 6. Anaphase I chromosome distribution during desynaptic meiosis in S. violaceum

\begin{tabular}{|c|c|c|c|c|c|}
\hline \multirow{2}{*}{$\frac{\text { S. no. }}{1 .}$} & \multicolumn{4}{|c|}{ Distribution } & \multirow{2}{*}{$\frac{\text { number cells }}{3}$} \\
\hline & 12 & & : & 12 & \\
\hline 2. & 11 & & $:$ & 13 & 4 \\
\hline 3. & 10 & & $:$ & 14 & 5 \\
\hline 4. & 9 & & : & 15 & 3 \\
\hline 5. & 8 & & $:$ & 16 & 1 \\
\hline 6. & 7 & & $:$ & 17 & 1 \\
\hline 7. & 11 & : & $1:$ & 12 & 2 \\
\hline 8. & $11+$ & $1 / 2$ & $: 1 / 2+$ & +12 & 2 \\
\hline 9. & 11 & $: 2$ & $1 / 2:$ & 12 & 1 \\
\hline 10 & 11 & & $: 21 / 2+$ & +12 & 1 \\
\hline 11. & 10 & : & $1:$ & 13 & 3 \\
\hline 12. & 9 & $: 2$ & $1 / 2:$ & 14 & 1 \\
\hline 13. & 8 & $:$ & $1:$ & 15 & 1 \\
\hline 14. & 7 & $: 2$ & $1 / 2:$ & 16 & 1 \\
\hline 15. & $7+$ & $1 / 2$ & $: 1 / 2$ & 16 & 2 \\
\hline 16. & 11 & : & $2:$ & 11 & 1 \\
\hline 17. & 10 & : & $2:$ & 12 & 1 \\
\hline 18. & $9+2$ & $1 / 2$ & $: 21 / 2$ & +13 & 1 \\
\hline 19. & $12+$ & $1 / 2$ & $: 31 / 2$ & +10 & 1 \\
\hline 20. & 9 & $:$ & $3:$ & 12 & 1 \\
\hline 21 . & 9 & $:$ & $4:$ & 11 & 1 \\
\hline 22. & 5 & : & $5:$ & 14 & 1 \\
\hline 23. & 7 & : & $5:$ & 12 & 1 \\
\hline 24 . & 5 & : & $11:$ & 8 & 1 \\
\hline
\end{tabular}

to 22 univalents; the highest frequency was of those having 4 I per cell (Table 3 ). The average per cell association was $9.26 \mathrm{II}+5.47 \mathrm{I}$. Metaphase chiasma frequency was 12.23 per cell and 1.28 per bivalent (Table 1). Majority of the anaphases showed irregular chromosome dis- 
tribution (Table 6). Laggards, with or without chromatid separation were frequently observed. Pollen stainability was $2.6 \%$.

Microsporogenesis in a few flower buds collected on a single day followed Prakken's (Prakken 1943) complete type of asynapsis/desynapsis instead of the more frequent mediumstrong type described above. The chromosomes showed total absence of pairing at metaphase I with the result that 24 univalents were present in all the microspore mother cells (Fig. 10). Typical anaphases were lacking, instead the chromosomes showed fragmentation leading to clusters of many chromatin fragments (Fig. 11).

Table 7. $t$ values obtained by comparing chiasma frequency during normal meiosis and desynaptic meiosis in Solanum species

\begin{tabular}{cccc}
\hline Species & Interstitial & Terminal & Total \\
\hline$S$. torvum & $10.964^{* *}$ & $18.997^{* *}$ & $26.362^{* *}$ \\
per cell & $2.753^{* *}$ & $6.869^{* *}$ & $17.661^{* *}$ \\
per bivalent & & & \\
$S$. melongena & $3.440^{* *}$ & $9.786^{* *}$ & $11.801^{* *}$ \\
per cell & 0.422 & $4.131^{* *}$ & $4.808^{* *}$ \\
per bivalent & & & \\
$S$. violaceum & $8.013^{* *}$ & $4.121^{* *}$ & $20.686^{* *}$ \\
per cell & $6.652^{* *}$ & 1.587 & $7.881^{* *}$ \\
per bivalent & & & \\
\hline
\end{tabular}

** $t$ values significant at 0.01 probability level

\section{Discussion}

In northern India, the main flowering season for $S$. melongena and $S$. violaceum is extended over the warmer months of the year (May-November) while for $S$. torvum it is early summer and monsoon (March-April and September-November). During these seasons, microsporogenesis followed by flowering and seed set were normal in all the 3 species. During off-season flowering i.e. winter in the first 2 species and summer in the last one, meiosis was abnormal which consequently resulted in sterility and poor or no fruit and seed set. Abnormal meiosis was found in all the plants of the varieties/accessions investigated and in the case of $S$. melongena and $S$. violaceum during both the successive winter seasons of study. Disrupted meiosis is obviously an effect of environmental stress; more particularly temperature stress since irrigation and fertilizer were provided at uniform intervals throughout the year. The adverse effects of temperatures higher or lower than the optimum on flowering and fruit set are well known (Went and Sheps 1969). On the process of microsporogenesis these effects are expressed in the form of blockage of meiosis, abnormal meiosis, abnormal tapetal development, collapse of microspores and anthers and pollen non-germinability (Whyte 1975). In the presently investigated species, the effects are primarly on the mechanism of chromosome pairing and segregation and, in the case of $S$. torvum, on the development of flowers also.

The appearance of univalents at metaphase $I$ in forms with normal chromosome homology is due to either desynapsis or asynapsis depending upon whether or not there is any initial chromosome pairing. Both the phenomena are known to occur in plants (Gottschalk and Baquar 1971, Gottschalk and Kaul 1980a, 1980b, Koduru and Rao 1981, Kaul and Murthy 1985 ). In $S$. torvum, the average frequency of bivalents at diplotene during the presently investigated aberrant meiosis was 11.21 per cell, a figure close to 12 bivalents formed during the normal meiosis. At metaphase, this figure dropped to 5.72 per cell. The chromosomes obviously fell apart between diplotene and metaphase. This species thus represents a case of 
desynapsis. In the other 2 species, pachytene or diplotene stages were not available for the study of early chromosome pairing behaviour. However, probably these are desynaptics too since the bivalent frequency at metaphase is no lesser, and is in fact higher, than that of desynaptic $S$. torvum. Furthermore, many previously reported cases of asynapsis have turned out to be desynapsis after critical examination of early meiosis (Celarier 1955). However, asynapsis appears to be the more likely cause of complete lack of chromosome pairing in microspores of some flower buds of $S$. violaceum detailed in Observations. Adverse effects of environmental stress can take place very early in meiotic cycle, e.g. between premeiotic mitosis and the start of DNA synthesis (Bayliss and Riley 1972b). The occurrence of a particular type of abnormality must depend upon the stage of division at which the stress sets in. Exposure to adverse conditions before or at critical stages of pairing would lead to asynapsis whereas somewhat later exposure would cause desynapsis. With the flower buds of the presently investigated plants experiencing temperature stress at different stages of development the appearance of more than one type of abnormality is quite expected. Thus besides desynapsis and probable asynapsis, chromosome breakages in $S$. violaceum and complete cessation of flower growth after bud stage in $S$. torvum represent a syndrome of temperature related effects. In Lolium, Jain (1957) reported inactivation of nucleolar organizing activity due to high temperature leading to the appearance of several small nucleoli instead of single large one. In Lolium and wheat, high temperature resulted in differential condensation of bivalents (Jain 1957, Rana 1965). Chromosome breakage during desynapsis has been reported in Sorghum (Magoon et al. 1961) and Allium (Koul 1962).

The effect of temperature stress in reducing chiasma frequency and in extreme conditions leading to asynapsis/desynapsis, has been reported by a number of workers (Darlington 1940, Barber 1942, Elliot 1955, Dowrick 1957, Wilson 1959a, b, Baylliss and Riley 1972a, Hossain 1978, Lin 1982). In the desynaptic $S$. torvum, since the chromosomes pair almost normally till diplotene the desynaptic effect is obviously brought about by rapid terminalization of chiasmata between diplotene and metaphase. Comparisons of chiasma frequency reveal that desynapsis in all the 3 species is accompanied by reduction in not only the per cell but also the per bivalent chiasma frequency (Table 7). These results indicate that all the bivalents experience uniform reduction in chiasmata due to temperature stress. With the number of chiasmata per bivalent during normal meiosis ranging between 1 and 3 , those with fewer chiasmata terminalize rapidly while others retain their integrity till the metaphase. Reduction in per bivalent chiasma frequency in $S$. torvum is due to reduction in both the terminal and the interstitial chiasmata while in the other 2 species it is due to decrease in only one of these.

In a review of the reproductive behaviour and distribution of Gramineae in western Monsoon Asia, Whyte (1975) concluded that the adverse environments experienced by the species at the peripheries of their distribution have led to several cytological abnormalities like meiotic failure, aberrant meiosis, apomixis, polyploidy etc. The author opines that the chromosomal and other variants thus produced have played a significant role in the evolution and speciation of these taxa. Among the present species, $S$. violaceum (better known by its synonym $S$. indicum) and $S$. melongena are native to India while $S$. torvum is exotic but widely naturalised here (Deb 1979, Whalen 1984). Taking anaphase chromosome distribution as an index, the occurrence of desynapsis under certain environmental conditions provides recurring chances of the origin of aneuploids in all the 3 species. Selfing, however, did not yield any viable seeds. Nor is there any previous record of aneuploidy among the several chromosome number reports made in these species (Fedorov 1969, Kumar and Subramanian 1986). Thus even though there has been a mechanism of the evolution of aneuploids, the latter have not been able to arise and/or establish; a fact which puts to doubt the evolutionary significance of such meiotic abnormalitites in these species. 


\section{Summary}

Microsporogenesis was normal during summer in $S$. melongena and $S$. violaceum and during monsoon in $S$. torvum. The same plants showed desynapsis during other seasons of flowering; winter in the first 2 species and summer in the last one. Normal meiosis was characterized by the chromosomes pairing into 12 bivalents, regular segregation and high pollen fertility $(86.5 \%-94.6 \%)$. Average per cell chromosome association at metaphase I during desynaptic meiosis was $5.72 \mathrm{II}+12.56 \mathrm{I}$ in $S$. torvum, $7.63 \mathrm{II}+8.73 \mathrm{I}$ in $S$. melongena and $9.26 \mathrm{II}+5.47 \mathrm{I}$ in $S$. violaceum. Microspore mother cells in a few flower buds of $S$. violaceum showed complete lack of pairing which may represent a case of asynapsis. Anaphase I showed irregular segregation, univalent laggards and precociously separating chromatids. In $S$. torvum, flower development stopped after microsporogenesis so that no pollen grains were formed. Pollen stainability in the other 2 species was low $(2.6 \%$ in $S$. violaceum and $14.7 \%$ in $S$. melongena). Both per cell and per bivalent chiasma frequency were reduced during desynaptic meiosis. Desynapsis and the other observed abnormalities are ascribed to temperature stress.

\section{Acknowledgements}

The author expresses his thanks to Dr. R. S. Rana, Director, N.B.P.G.R. for facilities. Keen interest and encouragment of Dr. K. P. S. Chandel, Joint Director, N.F.P.T.C.R. is gratefully acknowledged. The programme is financed by Department of Biotechnology, Govt. of India.

\section{Literature cited}

Barber, H. N. 1942. The experimental control of chromsome pairing in Fritillaria. J. Genet. 43: 359-374

Bayliss, M. W. and Riley, R. 1972a. An analysis of temperature-dependent asynapsis in Triticum aestivum. Genet. Res., Camb. 20: 193-200.

- and - 1972b. Evidence of premeiotic control of chromsome pairing in Triticum aestivum. Genet. Res., Camb. 20: 201-212.

Celarier, R. P. 1955. Desynapsis in Tradescantia. Cytologia 20:69-83.

Darlington, C. D. 1940. The prime variables of meiosis. Biol. Rev. 15: 307-321.

Deb, D. B. 1979 . Solanaceae in India in Hawkes, J. G., Lester, R. N. and Skelding, A. D. (ed.) The Biology and the Taxonomy of the Solanaceae. Academic Prees, London. pp. 87-111.

Dowrick, G. J. 1957. The influence of temperature on meiosis. Heredity 11:37-49.

Elliot, C. G. 1955. The effect of temperature on chiasma frequency. Heredity 9: 385-398.

Fedorov, An. A. 1969. Chromosome Numbers of Flowering Plants. Academy of Sciences of the USSR, Leningrad.

Gottschalk, W. and Baquar, S. R. 1971. Desynapsis in Pisum sativum induced through gene mutation. Can. J. Genet. Cytol. 13: 138-143.

- and Kaul, M. L. H. 1980a. Asynapsis and desynapsis in flowering plants I. Asynapsis. The Nucleus 23: $1-15$.

- and - 1980b. Asynapsis and desynapsis in flowering plants II. Desynapsis. The Nucleus 23: 99-120.

Hossain, M. G. 1978. Effect of external environmental factors on chromosome pairing in autotetraploid rye. Cytologia 43: 21-34.

Jain, H. K. 1957. Effect of high temperature on meiosis in Lolium: nucleolar inactivation. Heredity 11: 23-36.

Kaul, M. L. H. and Murthy, T. G. K. 1985. Mutant genes affecting higher plant meiosis. Theor. Appl. Genet. 70: $449-466$.

Koduru, P. R. K. and Rao, M. K. 1981. Cytogenetics of synaptic mutants in higher plants. Theor. Appl. Genet. 59: 197-214.

Koul, A. K. 1962. Desynapsis and spontaneous chromosome breakage in Allium cepa. Phyton 19:115-120.

Kumar, V. and Subramanian, B. 1986. Chromosome Atlas of Flowering Plants of the Indian Subcontinent. Botanical Survey of India, Calcutta. 
Lin, Y. J. 1982. Temperature and chiasma formation in Rhoeo spathacea var. variegata. Genetica 60: 25-30.

Magoon, M. L., Ramanna, M. S. and Shambulingappa, K. G. 1961. Desynapsis and spontaneous chromosome breakage in Sorghum purpureosericeum. Indian J. Genet. 21: 87-97.

Nothmann, J. and Koller, D. 1973. Morphologenetic effects of low temperature stress on flowering of eggplant, Solanum melongena L. Israel J. Bot. 22: 231-235.

Prakken, R. 1943. Studies of asynapsis in rye. Hereditas 29: 475-495.

Rana, R. S. 1965. A cytological evaluation of temperature sensitivity in diploid wheat. Caryologia 18: 117125 .

Som, M. G. and Maity, T. K. 1986. Brinjal in Bose, T. K. and Som, M. G. (ed.), Vegetable Crops in India. Naya Prokash, Calcutta. pp. 293-342.

Went, F. W. and Sheps, L. O. 1969. Environmental Factors in Regulation of Growth and Development: Ecological Factors in Stewart, F. C. (ed.) Plant Physiology-A Treatise vol. VA : Analysis of Growth: Behaviour of Plants and Their Organs. Academic Press, New York. pp. 299-406.

Whalen, M. D. 1984. Conspectus of species groups in Solanum subgenus Leptostemonum. Gentes Herbarum 14: $179-282$.

Whyte, R. O. 1975. The geography of abnormal meiosis in plants. The Nucleus 18: 183-203.

Wilson, J. Y. 1959a. Temperature effect on chiasma frequency in the blue bell, Endymion nonscriptus. Chromosoma $10: 337-354$

- 1959b. Chiasma frequency in relation to temperature. Genetica 29: 290-303. 